\title{
CybHER: A Method for Empowering, Motivating, Educating and Anchoring Girls to a Cybersecurity Career Path
}

\author{
Pam Rowland \\ Dakota State University \\ pam.rowland@dsu.edu
}

\author{
Ashley Podhradsky \\ Dakota State University \\ ashley.podhradsky@dsu.edu
}

\author{
Stephanie Plucker \\ Dakota State University \\ splucker@pluto.dsu.edu
}

\begin{abstract}
There are challenging problems to solve in cybersecurity. We must engage women as an untapped resource in our national effort to protect our country and critical infrastructure. Developing original ways to engage young women serves to address this recognized national need for recruitment through security education at the K-12 and undergraduate level. This would further address the widening gap between the availability and demand for qualified and diverse security professionals. Designing security iterations that are creative, socially relevant, and accessible to an underrepresented population in cybersecurity is a challenge that informs how education and outreach can be performed within other contexts. This research will discuss the CybHER model for engaging and supporting young women in cybersecurity while anchoring them to this field. By providing 5 different interventions, CybHER seeks to empower, motivate, educate, and anchor girls to cybersecurity. Further, existing CybHER outreach activities and lessons will be discussed.
\end{abstract}

Keywords: cybersecurity, gender gap, education, outreach, retention, social media, design science

\section{Introduction}

Cybersecurity is a critical component to counteract cybercrime and cyber terrorism. Cybercrime, including cyber terrorism, is predicted to cost the world $\$ 6$ trillion annually by 2021 . The cybersecurity market grew from $\$ 3.5$ billion in 2004 to $\$ 75$ billion in 2015 , with a forecast of reaching $\$ 170$ billion by 2020 [1]. Cyber threats are increasing and becoming more sophisticated causing the demand for cybersecurity professionals to grow. The human capital crisis is one of the most significant obstacles we face to meet this need. By the year 2020, there is expected to be a deficit of 1.5 million professionals in the information security field [2]. In 2016, only $11 \%$ of information security professionals were women, therefore, retaining and growing the number of women in cybersecurity is key to addressing the shortfall of trained professionals while improving the diversity of thought that experts state will strengthen our national security [3-5]. We have many challenging problems in the field of cybersecurity and for that reason alone we must engage women as an untapped resource in our national effort to protect our country and critical infrastructure.

Awareness of cyber careers is growing from the many enrichment activities that have been ongoing worldwide in the recent years. These activities include career exploration incentive programs, clubs, job fairs, competitions, scholarships, mentoring programs, and camps. A Raytheon-NCSA 2016 report indicated that $26 \%$ of the young people surveyed were more aware of these opportunities from the previous years, however the gender gap maintains with nearly twice as many men as there are women knowing about these activities [6].

Cybersecurity is critical to protecting our national security. It is imperative that we continue to research ways to conduct outreach and retention for women in cybersecurity. This research answers the question of, "What is a comprehensive program model that can effectively motivate, educate and anchor girls to a cybersecurity career path?"

\section{Literature Review and Theoretical Foundations of CybHER}

CybHER is grounded in career development research and seeks to anchor girls to a career in cybersecurity. The career anchor theory was first developed by Schein [7], who later described a career anchor as "his or her self-concept, which consists of self-perceived talents and abilities, basic values, and evolved sense of motives and needs as pertaining to a career" [8]. Schein's research shows that this selfconcept evolves over time, however once formed, "it functions as a stabilizing force, an anchor, and can be thought of as the values and motives that a person will not give up if forced to make a choice" [8]. Fifty percent of women leave the cyber field within 12 years [9], a rate more than two times what it is for men [10] 
and $10 \%$ more than the already abysmal attrition rate for women in general engineering [11]. Creating anchors is a necessity to achieve a vibrant and diverse workforce. Anchors can be identified and created through education and outreach [12].

This leads to a very important question, how can anchors be formed? Schein identifies eight anchors that most people's self-concepts revolve around. These include 1) autonomy/independence; 2) security/stability; 3) technical-functional competence; 4) general managerial competence; 5) entrepreneurial creativity; 6) service or dedication to a cause; 7) pure challenge; 8) life style. Later in this paper, we will tie the career anchor theory to our method's themes.

Other factors that will be considered when looking at forming anchors unique to female students are recovering from failure, socialization, problem-based curriculum, collaborative learning, and mentorship.

While our research is focusing on reaching girls for cybersecurity, we look to research focused on computer science as the closest example. Unique to female computer science students is an inherent disadvantage when recovering from a failure early in their studies. For experienced and confident CS students (which are, currently, disproportionately boys), incessant and abject failure does little to damage their faith in their own abilities. For those new to the discipline, though, a constantly reinforced message of failure leads to low self-esteem, diminished confidence, and a re-consideration of career goals [13]. Knowledge and practice can lead to confidence and self-efficacy [14, 15]. Inspirational messages and independent exploration lead to motivation [16].

Socialization and mentorship uniquely benefit young women and address many of the deficiencies found in more traditional approaches to cybersecurity education for this population. A study by Elaine Seymour found that socialization for young women is one of the keys to engagement and allows them to attach and engage in a line of study. Specifically, her research states, "...the socialization of most young women encourages the development of more extrinsic sense of identity [17]." By exposing young girls to cyber interests through social activities, they can better identify with others and with their own interests. When a girl's work is recognized, supported, and given opportunities, girls view their potential and future selves [18]. Females respond well to collaborative learning and the ability to have student-to-student interaction [19, 20], and problem-based curriculum can lend itself to collaborative learning as well as peer interaction [21].
Katz (2006) found that females who have friends in their department are more likely to persist in computer science. Peterson (2015) has similarly shown the positive effects of socialization using similar strategies in teaching cybersecurity to undergraduate women. His first-year course in cybersecurity overcomes many of the common shortcomings identified in typical CS coursework by communicating a real-world context and the social relevance of the discipline, dispelling notions of cyber as a solitary, misanthropic, and isolating pursuit, and showing how creativity and individual expression are beneficial and necessary for success as a security professional [22]. Community supports a strong identity, and collaborative problem solving gives purpose [23-25].

Mentorship and family involvement provides encouragement, support, and helps girls identify those "like them" in the field of cyber. Emphasizing social connections and shared culture beyond the classroom, has been found to be an effective measure to retain female students in computing degrees [26]. Constant connection and supportive and engaged guardians lead to positive and long-lasting influence [27-29].

CybHER will provide multiple opportunities for social connections and a shared culture, in a variety of settings and modes, which will translate into more females entering the cyber field and being anchored to the discipline.

\section{Problem identification and motivation}

While there are several theories and enrichment activities, none specifically brought a comprehensive solution that could provide a consistent and lasting impact to girls. By looking at Schein's anchor theory as well as other theories unique to girls in computing, we develop intervention themes that will create anchors and motivation from an earlier age.

This research goes beyond tailoring the contents of our interventions, it aims to change the mechanism of delivery. The intent of this study is to design and develop a comprehensive learning environment, in the form of CybHER, that not only adds to the research literature of theories to increase participation of girls in cyber, but also is a valuable method for programs with the same goals.

Not only would this serve to address a recognized national need, it would begin to address the gap between availability and demand for qualified and diverse security professionals. Designing security interventions that are creative, socially relevant, and accessible to an underrepresented population in 
cybersecurity is a challenge that informs how education and outreach can be performed within other contexts. CybHER will foster positive and encouraging relationships, create a pipeline of role models and a self-sustaining support system, introduce more girls to cybersecurity, and transition them into collegiate programs that will ultimately provide qualified and successful professionals.

\section{Objectives}

CybHER is building a community of knowledge, inspiration, and mentorship. By reaching out and providing positive experiences to girls at an earlier age, anchors can be formed, confidence built, and commitment made to the discipline. This is easier said than done. Early experiences need to be combined with a tailored message that avoids negative stereotypes of the field; provide mentoring opportunities to show what success "looks like;" leverage exercises that instill purpose; give opportunities for "productive failure;" and ensure a positive and supportive environment for the same. All of which have shown to be factors that help women persist in a cyber career path [30-34].

\section{Design and Development}

CybHER is an intervention method to educate and motivate girls to pursue cybersecurity. This project utilizes design-based research to develop intervention in an educational setting. It is intended to improve education and inform theory. This intervention is designed and then implemented [35]. In order for others to understand the intervention, the design and the implementation need to be documented [36].

All elements required for Design Science research are included:
- It identifies an existing, important, persistent, unsolved IS problem.

- The proposed solution is a novel artifact informed by reference theories, intended to be used to solve a problem.

- The steps of requirements-gathering, solution design, and observation constitute the evaluation phase.

- The framework can be applied to other projects or programs wishing to increase awareness and diversity. [37]

With these guidelines, this section will focus on the current design of CybHER.

CybHER is organized into five separate, but thematic, interventions. Previous approaches have provided positive but intermittent exposure, while CybHER is designed to be comprehensive and provide continuous engagement with cybersecurity concepts throughout a student's curricular and extracurricular life. Figure 1 shows the CybHER Themes. Each theme forms a pillar to the entire CybHER program. Each area is essential to build on the theoretical background regarding empowering, motivating, educating, and anchoring girls to cybersecurity. Without each pillar, a piece would be missing.

The CybHER themes recognize time as an important element to girls. Each theme is developed around this sense of time allowing for varied amounts of time interventions. Each theme also addresses theoretical concepts found through literature and expertise. While the CybHER themes are paramount to our program, we will have emerging aspects of our program including CybHER Tips, CybHER Warrior, CybHER Motivation, etc. This will help add new content to our program. 


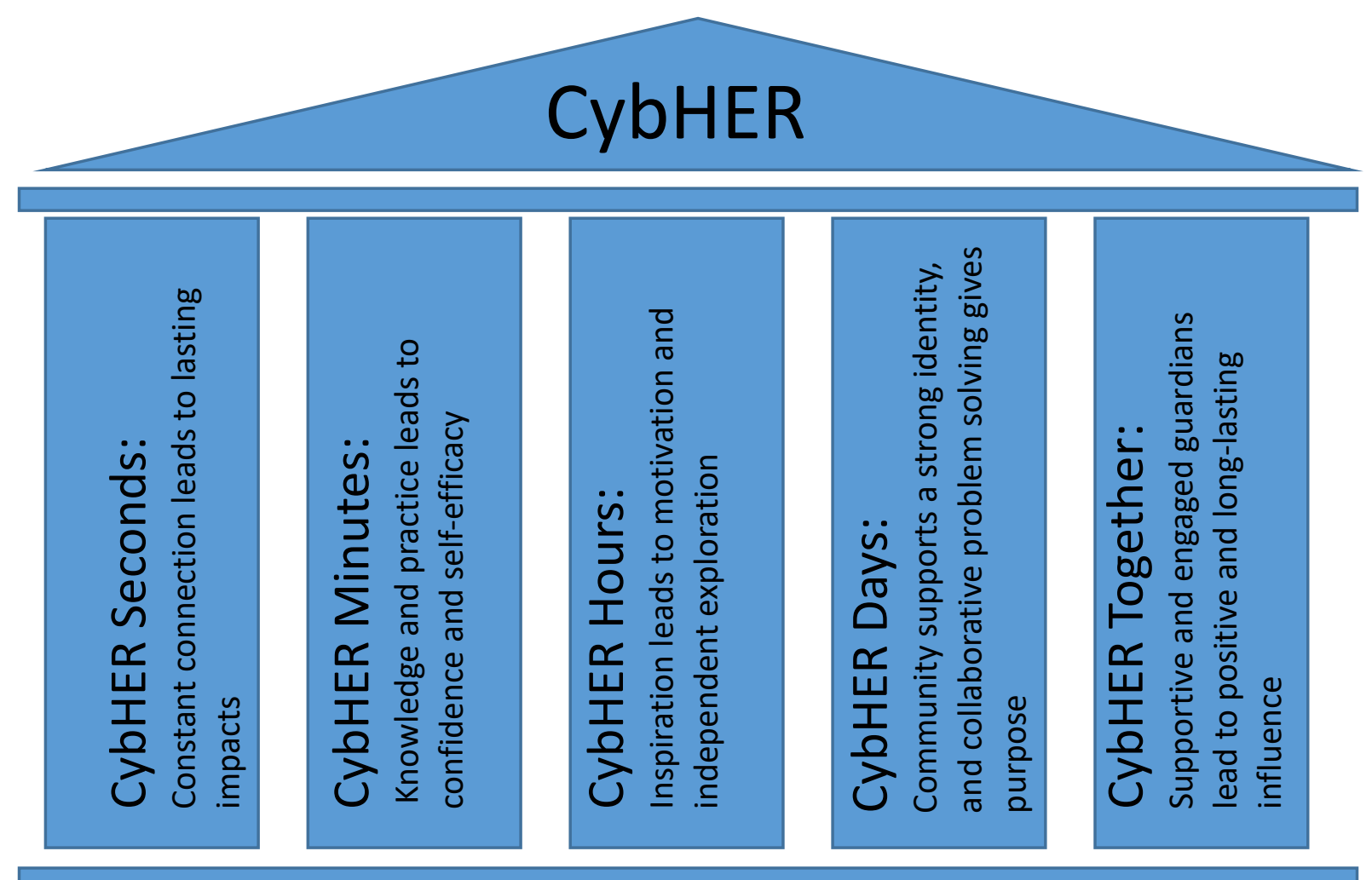

\section{Career Development Research}

Figure 1: CybHER Themes

\subsection{CybHER Seconds}

Constant connections lead to lasting impacts [29]. One of the goals of CybHER is to stay connected. CybHER Seconds are frequent connections on different platforms for inspiration, connection, and to showcase current events and technological developments. Emails, tweets, snaps, and Instagrams are used to maintain communication with participating girls. These quick connections take seconds, thus the title to this pillar. On average, we have 2-3 social media posts a week to be a constant connection with our audience.

The content is focused on cybersecurity awareness, current events, upcoming CybHER events, new engagement opportunities, CybHER tips, and CybHER motivation. Seconds are tailored to the target population, designed to be accessible, interesting, and relevant to girls aged 12 to 21 .

\subsection{CybHER Minutes}

Knowledge and practice leads to confidence and self-efficacy $[14,15]$. Providing informal, independent educational opportunities to girls will help build their confidence and excitement for this field. CybHER Minutes are engaging 3-5 minute videos and short 5-7 minute follow-up exercises that provide the girls with foundational knowledge about mainstream topics in cybersecurity. The videos will cover topics like cryptography, phishing, social engineering, internet of things, the dark web, smart phone security, and much more. Beyond being strictly theoretical, the videos will demonstrate these topics using technologies relevant to young women, and be explicit about the need for their participation in the discipline, the impact they can make, the excitement in field, and the problems they can help solve. This would inspire independent exploration, promote self-efficacy, and cause the girls to build a passion for cybersecurity. 


\subsection{CybHER Hours}

Inspiration leads to motivation and independent exploration [16]. CybHER Hours will be long-form, thirty to forty minute, inspirational videos created by leading women across the world in industry, government, research, and academia discussing their careers and areas of expertise.

These long-form videos will motivate and inspire girls through the stories of successful women. Our subjects will share how cybersecurity can lend itself to a fulfilling career as well as a fulfilling and balanced life. It is important for girls to view other women in a wide-range of jobs and employment statuses as successful role models in cybersecurity, allowing students to envision themselves in similar, important careers in cybersecurity. The videos will also work to defy gender and other stereotypes. All too often there is a perception of "tech" people working alone in a cubical. The videos will show successful women working in defiance of this assumption, talking about what they do, how they became a cyber professional, and sharing their goals for the future.

\subsection{CybHER Days}

Community supports a strong identity, and collaborative problem solving gives purpose [23-25]. It is well understood that girls can excel when there is community and support. In its simplest form, CybHER Days consist of students gathering together for a day of community and learning.

These events provide learning and exploration in a community setting where girls can identify with a group, develop social belonging, and receive mentorship, which leads to an anchor in the field.

CybHER Days provide opportunities for leadership. Girls team together and work towards accomplishing goals and learning in a supportive and encouraging environment.

CybHER Days are held at schools, universities, or public locations. An example of a CybHER Day includes learning programming, networking, and security concepts through hands-on exercises. It also includes problem solving, community building activities, and creative use of technology.

\subsection{CybHER Together}

Supportive and engaged guardians lead to positive and long-lasting influence [27, 28]. Whereas the popular Mommy and Me and Daddy and Me classes (swimming, painting, cookie decorating, etc.) are used as a vehicle for skills building and bonding, CybHER Together reimagines this approach through the lens of cybersecurity.

CybHER Together addresses the need for supportive parents/guardians, who are highly influencial in their child's career choice, but may not be aware of the opportunities available in cybersecurity. An October 2016 report by the National Cybersecurity Alliance and Raytheon, revealed that millennial students were most influenced by their parents when dealing with career advice [6]. CybHER Together seeks to not only educate parent and child, but also to provide a fun, learning environment for the parent/guardian and child. We have hosted several CybHER Together events that have taught girls how to code robots, learn encryption, and work with their parents to learn more about cyber. Currently we have held events at the local library and science centers.

\subsection{Image}

Many middle-school and high school youth know the value of attending events to increase education and learn more about cybersecurity, yet schedules and family life will often limit their ability or motivation to attend. It is also during this time that students need to continue to learn and socialize. Research indicates that marketing, relationships, resources, and providing a benefit, draw student to the programs [38, 39].

To reach middle-school and high-school girls, a mascot has been created called CybHER Girl (Figure 2).

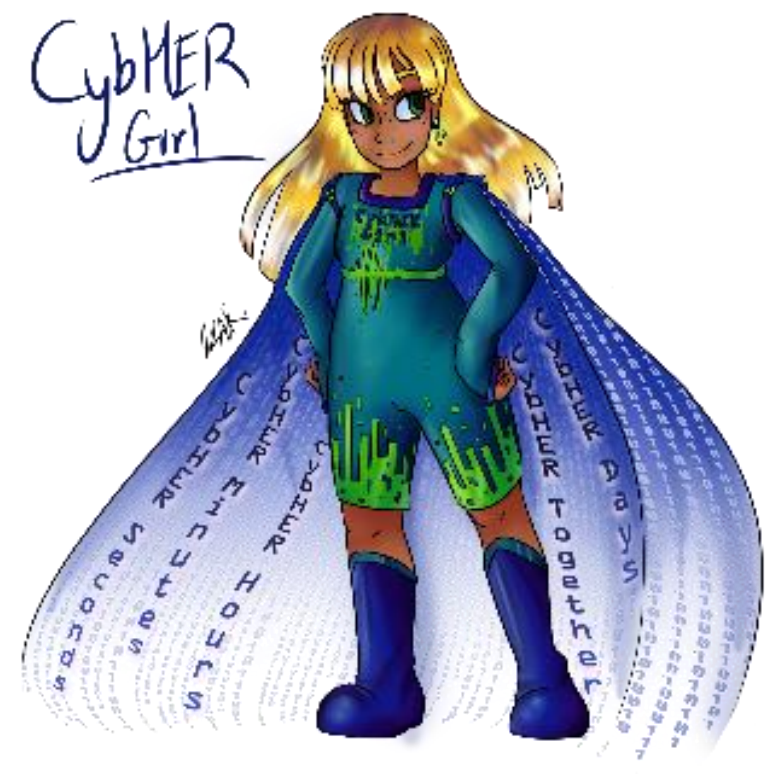

Figure 2: CybHER Girl 
This figure was created to be powerful, confident, and provide a way for young girls to connect to the program. Each area of CybHER gives the CybHER Girl her power to learn, be motivated, and achieve results.

\section{Anchors}

This project seeks to start anchors in the middle school years. Each of these themes can be tied to Schein's Career Anchors with the goal to start these anchors as soon as middle school. Schein indicates that people discover and thus identify one or more anchors as their careers evolve [8]. While the target audience of this research are not developing their careers, and they may not discover their true anchors for many years, we would like to start to develop these anchors early. Anchors develop through time and as decisions and choices are made [8]. This concept becomes important and relevant as we work to fill the human capital need in cybersecurity as well as retain women in the field.

Table 1 connects Schein's Career Anchors to the CybHER Themes. As Schein stated, "The only reliable prediction is that we will have to become perpetual learners, more self-reliant, and more capable than ever in dealing with surprises of all sorts. It should be a field day for those anchored in pure challenge [8]." CybHER activities form anchors and give girls the opportunity to become perpetual leaners while allowing them to face challenges.

\section{Table 1: CybHER Anchor Themes}

\begin{tabular}{|l|l|}
\hline Schein's Career Anchor[8] & Supported CybHER Theme \\
\hline $\begin{array}{l}\text { Security and Stability -- Employment security as a } \\
\text { lifetime employee can no longer be relied upon as } \\
\text { companies shift and change. Anchoring in this area } \\
\text { has to be dependent on oneself. The only thing a } \\
\text { person can take from an organization is the } \\
\text { opportunity to learn and gain experience. This will } \\
\text { cause him or her to be more employable in some other } \\
\text { organization. }\end{array}$ & $\begin{array}{l}\text { CybHen have experienced security and stability, } \\
\text { therefore having foundational knowledge that this is } \\
\text { possible } \\
\text { CybHER Minutes, Days and Together - Learning }\end{array}$ \\
\hline $\begin{array}{l}\text { Autonomy/Independence - Individuals do not thrive } \\
\text { when being dependent on any particular organization. }\end{array}$ & $\begin{array}{l}\text { CybHER Seconds - constant self-learning } \\
\text { CybHER Minutes - self-learning and practice }\end{array}$ \\
$\begin{array}{l}\text { This group of people have high self-reliance. } \\
\text { Cybence }\end{array}$ & $\begin{array}{l}\text { CybHER Days - self-motivated to attend and learn } \\
\text { in a group }\end{array}$ \\
\hline $\begin{array}{l}\text { Life Style - Economic security is one aspect of a 'life } \\
\text { system', which is the larger part of life-style, } \\
\text { including personal and family concerns. Autonomy } \\
\text { and concern for self are also factors. This area } \\
\text { involves organizations supporting the family unit, } \\
\text { sabbaticals, and creative ways for employees to } \\
\text { complete their work. }\end{array}$ & $\begin{array}{l}\text { CybHER Hours - While this anchor is harder to } \\
\text { learning about professional women in the field. }\end{array}$ \\
\hline $\begin{array}{l}\text { Technical/functional Competence - Individuals } \\
\text { desire to feel competence and recognize the } \\
\text { importance of knowledge and skill and being life-long } \\
\text { learners. }\end{array}$ & $\begin{array}{l}\text { CybHER Seconds - constant self-learning } \\
\text { CybHER Minutes - self-learning and practice } \\
\text { CybHER Days - self-motivated to attend and learn } \\
\text { in a group } \\
\text { CybHER Together - learning with parent/guardian }\end{array}$ \\
\hline $\begin{array}{l}\text { General Managerial Competence - This anchor is } \\
\text { indicated through leadership and managerial skills. }\end{array}$ & $\begin{array}{l}\text { CybHER Days and Together - While students will } \\
\text { not be put into a work managerial setting, we believe }\end{array}$ \\
\hline
\end{tabular}




\begin{tabular}{|l|l|}
\hline $\begin{array}{l}\text { The individual with general management anchor is } \\
\text { generally after power, glory, responsibility, } \\
\text { accomplishment of a task, the ability to build and } \\
\text { manage a team, or a combination of these. }\end{array}$ & $\begin{array}{l}\text { that this anchor can start to develop through } \\
\text { CybHER Days where students can experience } \\
\text { leadership and learning. This can also happen during } \\
\text { CybHER Together where students are showing their } \\
\text { accomplishments to their parent/guardian. }\end{array}$ \\
\hline $\begin{array}{l}\text { Entrepreneurial creativity - This anchor relates to } \\
\text { developing one's own business. }\end{array}$ & $\begin{array}{l}\text { CybHER Hours - This anchor can start to form } \\
\text { through learning about entrepreneurial successes of } \\
\text { professional women. We believe it can also start to } \\
\text { form through CybHER Seconds, Minutes, Days, and } \\
\text { Together as students learn and experience. }\end{array}$ \\
\hline $\begin{array}{l}\text { Service/Dedication to a Cause - This anchor shows } \\
\text { that individuals want to do something meaningful. }\end{array}$ & $\begin{array}{l}\text { CybHER Seconds - constant connections on } \\
\text { worthwhile causes and service } \\
\text { CybHER Hours - seeing how others serve and are } \\
\text { doing something meaningful }\end{array}$ \\
\hline $\begin{array}{l}\text { Pure challenge - This career anchor involves } \\
\text { individuals that want to overcome the impossible odds } \\
\text { and solve the unsolved problems. They are active } \\
\text { learners and want to challenge themselves. }\end{array}$ & $\begin{array}{l}\text { All CybHER themes address this anchor by } \\
\text { challenging the students to learn and solve problems. }\end{array}$ \\
\hline
\end{tabular}

\section{Expected Results, Contributions and Discussion}

CybHER educates, motivates, encourages and produces anchors for girls in cybersecurity. This method will be tested over time through growth of participants and an increase in the number of girls entering the field.

Our ultimate dream is to have diversity within in the cybersecurity workforce that would see equal number of males and females. We also seek a qualified workforce to fill the enormous number of cybersecurity jobs that are open in our nation. Diversity of thought provides innovative solutions to cybersecurity problems.

\section{Conclusion}

The lack of cybersecurity professionals has never been more serious. Initiatives to raise awareness over the last decade have resulted in a small amount of fruit. These initiatives and educational opportunities for students need to continue to grow and expand. It is important that females are receiving information and education about opportunities in cybersecurity. While the gender gap is nothing new, research does show that the trend is continuing. There is not one simple answer to solve the cybersecurity workforce shortage, but each positive step is a step in the right direction. These continued and sustainable efforts are required to meet the ever-increasing need. The CybHER program has the potential to immediately affect the diversity and quality of students pursuing a cybersecurity career path. Designing relevant, fun, and engaging security activities for girls that synergize with existing K-12 outreach programs, builds interest in existing programs, diversifies programs, engages new audiences, and educates on the fact that cybersecurity is relevant. Given our target audience is young, we need time to see if our efforts lead to increased enrollment in collegiate programs, then highly skilled workers. Our dissemination strategy has the potential to impact and partner with other projects nationally.

CybHER is an exciting endeavor to mentor and stay connected with girls. It seeks to inspire, motivate, educate, anchor, and walk alongside girls as they discover this fascinating field. The community created will be far reaching, and act as a catalyst for positive influence of change in an area that so desperately needs more diversity. As Grace M. Hopper (computer programmer 1943), once said, "The most dangerous phrase in the language is: We've always done it this way." CybHER seeks to do it differently.

By empowering, motivating, educating, and changing perceptions of girls and women toward cybersecurity, CybHER provides anchors to this field. 


\section{References}

[1] S. C. Morgan, "Cybersecurity Market Report," Q4 2016, Available:

http://cybersecurityventures.com/cybersecuritymarket-report/.

[2] N. Nolte, "Despite Growing Cyber Threats and Workforce Gap, Women Remain

Underrepresented in Information Security," A.

Booz, Hamilton, Ed., ed, 2015.

[3] Memorandum for Heads of Departments and Agencies: Federa Cybersecurity Workforce Strategy.

[4] D. Robey, "Research commentary: diversity in information systems research: threat, promise, and responsibility," Information systems research, vol. 7, no. 4, pp. 400-408, 1996.

[5] D. Frincke. (2017). Deborah Frincke and the Need for Diversity of Perspective in Cybersecurity. Available: http://cybersecurity.ieee.org/blog/2016/09/20/deb orah-frincke-and-the-need-for-diversity-ofperspective-in-cybersecurity/

[6] "Securing Our Future: Closing the Cybersecurity Talent Gap," Raytheon-NCSA2016, Available: http://www.raytheoncyber.com/rtnwcm/groups/c yber/documents/content/rtn 278208.pdf.

[7] E. H. Schein, "The individual, the organization, and the career: A conceptual scheme," The Journal of Applied Behavioral Science, vol. 7, no. 4, pp. 401-426, 1971.

[8] E. H. Schein, "Career anchors revisited: Implications for career development in the $21 \mathrm{st}$ century," The Academy of Management Executive, vol. 10, no. 4, pp. 80-88, 1996.

[9] J. L. Glass, S. Sassler, Y. Levitte, and K. M. Michelmore, "What's so special about STEM? A comparison of women's retention in STEM and professional occupations," Social forces, vol. 92, no. 2, pp. 723-756, 2013.

[10] S. A. Hewlett, The Athena factor: Reversing the brain drain in science, engineering, and technology. Harvard Business School Watertown, MA, 2008.

[11] S. Silbey, "Why Do So Many Women Who Study Engineering Leave the Field?," Harvard Business ReviewAugust 23, 2016.

[12] C. Noteboom and P. Rowland, "An Exploration of Anchoring Female Millennial Students to an IS/IT Career Path: The CLASS Model," in Proceedings of the 50th Hawaii International Conference on System Sciences, 2017.

[13] H.-Y. Huang and M. Bashir, "Examining the Gender Gap in Information Assurance: A Study of Psychological Factors," in International Conference on Human-Computer Interaction, 2015, pp. 117-122: Springer.

[14] B. W. Pelham, "On confidence and consequence: the certainty and importance of self-knowledge," Journal of personality and social psychology, vol. 60 , no. 4, p. 518, 1991
A. L. Zeldin and F. Pajares, "Against the odds: Self-efficacy beliefs of women in mathematical, scientific, and technological careers," American Educational Research Journal, vol. 37, no. 1, pp. 215-246, 2000.

[16] R. Geritz, K. Gumtov, T. Martin, G. Heron, and K. Summerfield, "Methods and systems for providing career inspiration, motivation and guidance to a user," ed: Google Patents, 2013. E. Seymour, Talking about leaving: Why undergraduates leave the sciences. Westview Press, 2000.

[18] A. C. Barton, H. Kang, E. Tan, T. B. O’Neill, J. Bautista-Guerra, and C. Brecklin, "Crafting a future in science tracing middle school girls' identity work over time and space," American Educational Research Journal, p. $0002831212458142,2012$.

[19] A. C. Graesser, N. K. Person, and J. P. Magliano, "Collaborative dialogue patterns in naturalistic one-to-one tutoring," Applied cognitive psychology, vol. 9, no. 6, pp. 495-522, 1995.

[20] W. M. Waite, M. H. Jackson, A. Diwan, and P. M. Leonardi, "Student culture vs group work in computer science," SIGCSE Bull., vol. 36, no. 1, pp. 12-16, 2004.

[21] S. Katz, D. Allbritton, J. Aronis, C. Wilson, and M. L. Soffa, "Gender, achievement, and persistence in an undergraduate computer science program," ACM SIGMIS Database, vol. 37, no. 4 pp. 42-57, 2006.

[22] T. Flushman, M. Gondree, and Z. N. Peterson, "This is not a game: early observations on using alternate reality games for teaching security concepts to first-year undergraduates," in 8 th Workshop on Cyber Security Experimentation and Test (CSET 15), 2015.

[23] V. Barr and C. Stephenson, "Bringing computational thinking to K-12: what is Involved and what is the role of the computer science education community?," Acm Inroads, vol. 2, no. 1, pp. 48-54, 2011.

[24] L. Springer, M. E. Stanne, and S. S. Donovan, "Effects of small-group learning on undergraduates in science, mathematics, engineering, and technology: A meta-analysis," Review of educational research, vol. 69, no. 1, pp. 21-51, 1999.

[25] L. Williams, E. Wiebe, K. Yang, M. Ferzli, and C. Miller, "In support of pair programming in the introductory computer science course," Computer Science Education, vol. 12, no. 3, pp. 197-212, 2002.

[26] J. P. Cohoon, "An introductory course format for promoting diversity and retention," $A C M$ SIGCSE Bulletin, vol. 39, no. 1, pp. 395-399, 2007.

[27] S. V. Turner, P. W. Bernt, and N. Pecora, "Why Women Choose Information Technology Careers: Educational, Social, and Familial Influences," 2002. 
[28] S.-M. Chai and M.-K. Kim, "A Road To Retain Cybersecurity Professionals: An Examination of Career Decisions Among Cybersecurity

Scholars," Journal of The Korea Institute of Information Security and Cryptology, vol. 22, no. 2, pp. 295-316, 2012.

[29] J. E. Bright, R. G. Pryor, S. Wilkenfeld, and J. Earl, "The role of social context and serendipitous events in career decision making," International journal for educational and vocational guidance, vol. 5, no. 1, pp. 19-36, 2005.

[30] L. Barker, C. L. Hovey, and L. D. Thompson, "Results of a large-scale, multi-institutional study of undergraduate retention in computing," in Frontiers in Education Conference (FIE), 2014 IEEE, 2014, pp. 1-8.

[31] J. Margolis, A. Fisher, and F. Miller, "Caring about connections: Gender and computing," Technology and Society Magazine, IEEE, vol. 18, no. 4, pp. 13-20, 1999.

[32] H. K. Tillberg and J. M. Cohoon, "Attaching women to the CS major," Frontiers: A Journal of Women Studies, vol. 26, no. 1, pp. 126-140, 2005.

[33] C. S. Dweck, Mindset: The New Psychology of Success. Ballantine Books, 2007.

[34] P. Tough, How Children Succeed: Grit, Curiosity, and the Hidden Power of Character. Houghton Mifflin Harcourt, 2012.

[35] A. Collins, D. Joseph, and K. Bielaczyc, "Design research: Theoretical and methodological issues," The Journal of the learning sciences, vol. 13, no. 1, pp. 15-42, 2004.

[36] C. M. Hoadley, "Methodological alignment in design-based research," Educational psychologist, vol. 39, no. 4, pp. 203-212, 2004.

[37] K. Peffers, T. Tuunanen, M. A. Rothenberger, and S. Chatterjee, "A design science research methodology for information systems research," Journal of management information systems, vol. 24, no. 3, pp. 45-77, 2007.

[38] S. Lauver and P. M. D. Little, "Finding the Right Hook," School Administrator, Article vol. 62, no. 5, pp. 27-30, 05// 2005.

[39] P. Little, S. DuPree, and S. Deich, "Documenting Progress and Demonstrating Results: Evaluating Local Out-of-School Time Programs," 2002. 